Lin, L., Robertson, A., \& Lee, J. (2012). The impact of outcome intentions on reading and multitasking performances. Journal of Educational Technology Development and Exchange, 5(1), 77-94.

\title{
The Impact of Outcome Intentions on Reading and Multitasking Performances
}

\author{
Lin Lin \\ University of North Texas \\ Adrian Robertson \\ Montana State University Billings \\ Jennifer Lee \\ University of North Texas
}

\begin{abstract}
This study investigated undergraduate students' reading comprehension between two outcome intentions and three media multitasking conditions. The two outcome intentions were for accuracy and completion. The three multitasking conditions included silence, video background, and video test conditions. One hundred thirty university students participated in the study. Every participant completed two sets of reading, with two different intentions and in two different conditions. Results showed that the participants performed better in reading (a) when they strived for completion than for accuracy, (b) that the addition of an unobtrusive video (video background) did not inhibit the processing of the primary reading task, and (c) that those who strived for task accuracy might have actually benefited from the addition of the background video. Implications of the results on multimedia design and student assessment are discussed.
\end{abstract}

Keywords: cognitive load, multitasking, outcome intention, multimedia learning

\section{Introduction}

We see students do it all the time: studying while watching television or switching between multiple programs on a computer. When asked how they accomplish what they are doing, the typical response is some version of "I multitask!" The propensity our students have for juggling multiple lines of input has no doubt been met with skepticism by those who want to see greater focus applied to the most important tasks at hand (Jackson, 2008). If our students are wavering in their attention while driving or are missing important information while studying, most would agree this presents a problem.

Whether one defines multitasking as the splitting of attention or as the rapid switching of attention between tasks (Baddeley, 
Chincotta, \& Adam, 2001; Burgess, Veitch, de Lacy Costello, \& Shallice, 2000; Monsell \& Driver, 2000), those who multitask are essentially trying to perform more task(s) over a shorter period of time. Usually one of the tasks is considered more important: when watching television while studying, for instance, gaining an understanding of the materials being studied would be the primary focus and all other tasks would be secondary. Whatever the overall tasks-performance outcome may be on all tasks combined, the researchers in this study are concerned with the outcome pertaining specifically to the primary task at hand. Even if multitasking is successful in that more tasks are accomplished in less time, what happens to the primary task? Even if there is an overall gain, what is being lost on the most important task of the moment? Answers to these questions have potentials to provide insights in important educational research and practices. The most obvious is when a studying task is paired with a competing task such as watching television. We need to understand whether a student is receiving sufficient information from the materials being studied and to what extent they are mastering the materials. Another situation is in the design of multimedia educational systems such as multi-user virtual environments (MUVEs) or computer-based learning environments. We must consider the warnings raised by the rich media paradox (Mayer \& Clark, 2007) or the inclusion of extraneous material (Nelson \& Erlandson, 2008), and avoid distracting students from their primary learning tasks. A third situation is in the assessment of student results, particularly where there is a distinction between gaining general knowledge versus gaining in-depth knowledge. We need to ensure that the measurement of the outcomes in multimedia situations takes into account the student's learning outcome goals. Each of these issues will be addressed in this paper.

\section{Theoretical Framework}

In this study, Cognitive Load Theory, Dual-Coding Theory, dual task, task switching, and Pareto Principle were referenced to help understand if students would perform reading comprehension differently when instructed to apply cognitive resources with different intentions and under different multitasking conditions. Each is briefly described below.

Cognitive Load Theory (Sweller, 1988) suggests that an individual carry three forms cognitive load while processing resources during a learning process. The first is intrinsic load that is imposed by the nature and difficulty level of the material being presented. The second is extraneous load that is imposed by the instructional methods and materials used. The third is germane load or the mental process of taking new information and integrating it with old information so that learning occurs. The addition of intrinsic, extraneous, and germane loads equals a learner's Total Cognitive Load (TCL). This raises two primary arguments: (1) extraneous load must be minimized to maximize the cognitive resources available to process the intrinsic and germane loads and (2) TCL cannot exceed the cognitive processing resources of the learner, or the learner shuts down under excessive load (Kirschner, 2002).

Dual-Coding Theory assumes that "humans possess separate information processing channels for visually represented material and auditorily represented material" (Mayer, 2001, p. 46). While encountering a new learning material, the learner has two primary channels of input available (Paivio, 1986). One is a verbal channel through which the learner processes words while the other is an imagery channel through which the learner processes images. Multimedia design principles are intended to maximize the 
flow of information through both channels in a manner that does not overload either one, or cause competition or redundancy between the information being processed, or require excessive distance in terms of time or space between the information processed (Mayer \& Moreno, 2003). Thus, good design minimizes extraneous cognitive load by filling both channels with complementary information without redundancy, confusion, or extra burden on working memory (Miller, 1956; Sweller, 1988). Poor design results in excessive extraneous processing and leaves little room for the germane processing required for learning. Mayer and colleagues categorized five types of cognitive overload scenarios that would apply to a multimedia learning situation (Mayer \& Moreno, 2003). First, the visual channel is overloaded with essential information. Second, both the visual and verbal channels are overloaded by essential information. Third, one or both channels are overloaded by a mix of essential and incidental information. Fourth, one or both channels are loaded with essential information that is presented in a confusing manner. Fifth, one or both channels are loaded with essential information that requires additional temporal storage and processing. It is important to examine these cognitive overload scenarios in various levels of multitasking situations.

Most studies focusing on multitasking show that one's ability to multitask is rather limited (Lang, 2001). Further, multitasking over different types of tasks reduces productivity (Just, Keller, \& Cynkar, 2008) and that one's ability to perform concurrent mental operations is limited by the capacity of the brain's central mechanism (Schweickert \& Boggs, 1984). Studies also find that it is more difficult to learn new things when one's brain is distracted by another activity (Poldrack \& Foerde, 2007). Scholars believe that switching between tasks wastes time because the brain is compelled to restart and refocus (Meyer \& Kieras, 1997). According to Just, Keller, and Cynkar (2008), each time when one has this alternation, there is a period in which one will make no progress on either task. However, neurological work over the last few decades also shows that our brains may be adapting to the demands of simultaneous tasks (Diamond, 2002). Small and Vorgan (2009) reported that Internet use and web-browsing have evident effects on our brains, which are much more changeable than most of us think, especially in the case of young people. Carr (2010) stated that our brains change in response to our experiences and that the technologies we use to find, store, and share information can literally reroute our neural pathways. Other studies have also suggested that practices and training may increase brain processing speed, improve working memory, and improve our ability to multitask (Jaeggi, Buschkuehl, Jonides, \& Perrig, 2008; Ruthruff, Van, Johnston, \& Remington, 2006). Some scholars believe that digital technologies have changed the way we retain and process information (Carr, 2010; Gee, 2003; Prensky, 2001).

This study was conducted under this context. The researchers believe it is important to understand what is involved and what is taking place when young people conduct several tasks at the same time, and to what extent their activities are beneficial or detrimental to their learning. Because our purpose was to investigate the cognitive processing resources the young people applied to the primary task, we set out to examine how intentions affect reading performance in multitasking conditions. The Pareto Principle shed lights on how outcome intentions might affect reading performance in a multitasking or multimedia learning environment. The Pareto Principle was originally derived from Vilfredo Pareto's early-20th-century observation that $80 \%$ of Italy's wealth belonged to only 
$20 \%$ of the population (Rushton, Oxlet, \& Croucher, 2000). This principle has later been more broadly used in various fields including economics and systems science to describe that, for many events, $80 \%$ of the effects are derived from $20 \%$ of the causes (Wilson, 1972). In terms of cognitive resource allocation, it is likely that people apply a small amount of attention to tasks where less-thanperfect outcomes are acceptable; expecting that roughly $20 \%$ of their allocated attention will result in $80 \%$ of the total possible result. In other words, if perfection is not required on the main task, a multitasking student might apply less attention to that task, and therefore, have more attention available to apply to other tasks than if a perfect outcome was required. Thus, it was expected that outcome intention would have an effect on the participants' processing resource allocation. Johnson (2005) described it vividly as follows: "It usually involves skimming the surface of the incoming data, picking out the relevant details, and moving on to the next stream. You're paying attention, but only partially. That lets you cast a wider net, but it also runs the risk of keeping you from really studying the fish" (p. 61). In addition to studying the effects of multitasking situations on the primary activity, the researchers wanted to investigate whether there are differences in the attentive allocation of participants, under various multitasking conditions, between those who were "casting a wider net" versus those who "really studied the fish." The following are research questions:

- Does reading comprehension performance differ when people intend to complete the reading task as quickly and as completely as possible (intention for completion) as compared to doing it as accurately as possible (intention for accuracy) in different multitasking conditions?
- What might be occurring with regards to the attentive resources of the participants when they multitask with different outcome intentions?

- If learning outcome intention affects one's performance, what does this mean for student assessment in a multimedia learning environment?

The purpose of this study, therefore, was to understand what changes would occur in students' focus and information acquisition in Multitasking Conditions when they had different learning Outcome Intentions.

\section{Method}

\subsection{Participants}

Undergraduate students from eight classes of the same course at a research university were invited to participate in this study during their regular class hours. The course was titled "Computers in the Classrooms." Students were given extra credit for participating in the study. One hundred thirty-seven students participated, but seven responses were determined to be unusable $(2.5$ standard deviations or more below the mean number of correct scores, with most questions simply left unanswered). This left 130 usable participant data-sets. The average age for the group was 23.9 years. Female students accounted for $90.7 \%$ of the participants. Male students accounted for the other $9.3 \%$. The gender disparity was largely due to the fact that female students outnumbered male students in the College of Education.

\subsection{Design and Procedure}

Two sets of reading materials were developed. Each set contained three articles: one article in science, one in history, and one 
in politics. All of the articles were similar in reading level, length, and format. Articles were selected based on the $8^{\text {th }}$ grade vocabulary level according to the "Flesch-Kincaid Grade Level Formula" (Kincaid, Fishburne, Rogers, \& Chissom, 1975).

Each article contained six multiplechoice questions. A total of six articles with 36 questions were used to assess the participants' reading comprehension for the study. The two sets of articles were equivalent in the numbers of words, with 2,478 words in one set and 2,439 words in the other set. Each set of articles was printed such that it contained the first article, questions for the first article, the second article, questions for the second article, the third article, and questions for the third article. Within each set, the sequence of the three articles was rotated during the data collection process so that no particular article was given priority.

In addition, two videos, each 16 minutes in length were developed. One video was a documentary on drunk-driving (Documentary), and another was a situational comedy (Sitcom). Six questions accompanied each video to measure the participants' video comprehension. The video comprehension tests were used in the video-background and video-test conditions. Finally, a survey was administered to gather data on demographic information and the participants' attention allocations. The participants were tested on both reading and video comprehension so that an authentic multitasking condition would be replicated; namely, watching television while reading or studying.

As shown in Table 1 below, students in each class completed two sets of reading comprehension tests in sequence, with one set under one multitasking condition and another set under a different multitasking condition. Because two out of three conditions involved videos, every participant watched at least one video. When the video was played, the participants were also asked to complete the six questions related to that video. The sequence of the conditions and the sequence of the videos used were alternated and balanced in the eight classes. For instance, if the previous class participated in the silence condition during the first 16 minutes and the video background condition during the second 16 minutes, then the following participating class would participate in the video background condition during the first 16 minutes and the silence condition during the second 16 minutes, and so forth. The same logic applied to the sequence of the videos used. If the previous class used the documentary video at the Video Background condition during the first 16 minutes of reading, then the following class would use the documentary video at the Video Background condition during the second 16 minutes of reading. The purpose of alternating and balancing the sequences of the conditions and videos used was to prevent the sequence of conditions or videos from affecting the results of the experiment.

In addition, the time was purposely set as limited; the participants had to complete each set of reading materials in 16 minutes, with or without a video. The participants were also instructed to finish one set of reading and questions as quickly and complete as possible (Intention for Completion), and to finish the other set of reading and questions as accurately as possible (Intention for Accuracy). Table 2 shows the numbers of participants by Multitasking Conditions and Outcome Intentions. 
Table 1. Data Collection: Sequence of Multitasking Conditions, Video(s) Used, and Numbers of Participants in Each Experimental Group

\begin{tabular}{|c|c|c|c|}
\hline \multirow{2}{*}{ Groups } & $\begin{array}{l}\text { First set of reading } \\
\text { (16 minutes) }\end{array}$ & $\begin{array}{l}\text { Second set of reading } \\
\text { (16 minutes) }\end{array}$ & \multirow{2}{*}{$\begin{array}{l}\text { Numbers of } \\
\text { Participants } \\
(n=130 \text { total })\end{array}$} \\
\hline & $\begin{array}{l}\text { Multitasking Condition } \\
\text { (Video Used) }\end{array}$ & Multitasking Condition (Video Used) & \\
\hline 1 & Silence (None) & Video Test (Documentary) & 16 \\
\hline 2 & Video Test (Sitcom) & Silence (None) & 19 \\
\hline 3 & $\begin{array}{l}\text { Video Background } \\
\text { (Documentary) }\end{array}$ & Silence (None) & 13 \\
\hline 4 & Silence (None) & Video Background (Sitcom) & 17 \\
\hline 5 & Video Background (Sitcom) & Video Test (Documentary) & 19 \\
\hline 6 & Video Test (Sitcom) & Video Background (Documentary) & 17 \\
\hline 7 & $\begin{array}{l}\text { Video Background } \\
\text { (Documentary) }\end{array}$ & Video Test (Sitcom) & 11 \\
\hline 8 & Video Test (Documentary) & Video Background (Sitcom) & 18 \\
\hline
\end{tabular}

Table 2. Numbers of Participants by Multitasking Conditions and Outcome Intentions

\begin{tabular}{ccccc}
\hline $\begin{array}{c}\text { Outcome } \\
\text { Intentions }\end{array}$ & Silence & $\begin{array}{c}\text { Multitasking Conditions } \\
\text { Video background } \\
\text { Condition }\end{array}$ & $\begin{array}{c}\text { Video test } \\
\text { Condition }\end{array}$ & $\begin{array}{c}\text { No. of } \\
\text { participants } \\
(\mathrm{n}=130)\end{array}$ \\
\hline Accuracy & 33 & 48 & 49 & 130 \\
Completion & 32 & 47 & 51 & 130 \\
\hline
\end{tabular}


Although the conditions were assigned at the existing class/group level, the Outcome Intentions were randomly assigned at the individual level with each class. That is, half of the class was randomly assigned "Intention for Accuracy" and the other half was randomly assigned "Intention for Completion" during the first 16 minutes of reading; those who were assigned "Intention for Accuracy" during the first 16 minutes of reading would switch to "Intention for Completion" during the second 16 minutes of reading and vice versa. This allowed all the students to participate in both Outcome Intentions. The total length of time each group of the participants took to finish the experiment was about 45-50 minutes. The following details the process of the data collection.

With each of the eight participating groups, materials were distributed as researchers explained what would be asked of the participants. First, general demographic information was collected. Second, instructions were given with regards to the Outcome Intentions. With the first set of reading, half of the participants were instructed to strive for Accuracy and the other half were instructed to strive for Completion. Further, if the Multitasking Condition was "video background," participants were told a video would be playing while they read and that they could either pay attention to it or not. They were not told there would be any questions asked of them concerning that video (although they were asked to answer the video questions for the experiment afterwards). In the Multitasking Condition with the "video test," participants were told a video would be playing while they read and that they would be tested on the video: they had to pay attention to both. The video (when used) played on a large screen at the front of the classroom, with speaker volume set at a comfortable level. Once the time was up for the first set of reading materials and questions (16 minutes), the participants answered questions regarding the video that played (in both video background and video test conditions). They were also asked to report how they split their attention between the reading and the video with the total attention equal to $100 \%$.

After a short break, the participants were given instructions with regards to the Outcome Intentions for the second set of reading materials. If the participant had been in the Intention for Accuracy with the first set, then he or she was instructed to assume the Intention for Completion with the second set, and vice-versa. As before, if the reading was not in the silence condition, then instructions were given regarding the video (video background or video test). When the time was up for the second set of reading and questions (also 16 minutes), the participants answered questions regarding the video and reported their attention allocations between the reading and video when the video was played. The Multitasking Condition used for the second half of the experiment differed from that used in the first half. In fact, the three Multitasking Conditions, the two Outcome Intentions, the two sets of reading materials, and the three articles within each set of reading materials, all were fully cross-checked and distributed in the way no Condition, Intention, or article was favored in priority.

Every participant received three points for every correct answer, so getting an answer correct was always fully rewarded (and answering all questions correctly always provided the best result). However, when the participants were assigned to the Intention for Accuracy, they were told they would lose one point for every incorrect answer, but would not lose a point if the question was left unanswered. When they were assigned to the Intention for Completion, they were told they would lose one point for every 
unanswered question, but would not lose a point if the question was incorrectly answered. These point scores were only used to award a few small gifts, and thereby, motivate the participants toward a particular Outcome Intention (being accurate or being complete as directed) that would provide the researchers with the opportunity to identify possible connections between the learners' reading performance and their Outcome Intentions. Data used for the analysis of this research however, was based upon the actual number of correct, blank, and incorrect answers.

\subsection{Manipulation Check}

Before moving forward with data analysis, manipulations were checked to see if the experimental design worked. The first manipulation was between the two Outcome Intentions (Intention for Accuracy versus Intention for Completion) and the second was between the two Multitasking Conditions (Video Background and Video Test Conditions).

In the Outcome Intention design, the researchers encouraged the participants to strive for either Accuracy or Completion. The researchers expected that the participants who strived for Accuracy would have a lower percentage of wrong answers while those who strived for Completion would have a lower percentage of blank answers. Therefore, to check the Outcome Intentions, the researchers examined the patterns of wrong and blank answers in the Intention for Accuracy and in the Intention for Completion scenarios. The data showed that the participants had a lower percentage of wrong answers $(12.3 \%$ versus $21.4 \%$ ) and a higher percentage of blank answers (20.3\% versus $1.2 \%)$ under the Intention for Accuracy than under the Intention for Completion. Logistic regression $(p<.01)$ and Chi-square analysis $(p<.01)$ indicated significant differences for the number of wrong answers, and significant differences for the number of blank answers. Further, each of these tests was completed separately for the data under each of the three Multitasking Conditions (silence, video background, and video test) with similar results. This set of tests indicated that the Outcome Intention manipulation was successful, and it was successful regardless of the Multitasking Conditions.

To check on the manipulation of the two Multitasking Conditions (video background and test conditions), the researchers looked at the percentage of attention the participants self-reported as having dedicated to the video versus the reading under the two conditions: those in the video test condition should report a higher percentage of attention applied to the video than those in the video background condition. While self-reports of attention percentages may not be as reliable as measured data, the researchers believe the participants' "subjective mental workload" to be reliable and accurate in its own right (Kalyuga, Chandler, \& Sweller, 2000; Paas, Tuovinen, Tabbers, \& van Gerven, 2003; Tuovinen $\&$ Paas, 2004). Those under the Video Background Multitasking Condition reported a lower percentage of attention paid to the video playing $(25.98 \%)$ than did those under the Video Test Multitasking Condition (38.63\%). Both a student's t-test $(p<.001)$ and a MannWhitney ranking test $(p<.001)$ between the two conditions indicated the difference was significant. In addition, the pattern of correct answers on the video tests was examined to see how attentive the participants were to the videos in these two conditions. As expected, when watching a video under the video background condition participants had a lower percentage of video correct answers (54.6\%) than when watching a video under the test condition $(66.2 \%)$. Logistic regression $(p<.01)$ and Chi-square analysis $(p<.01)$ indicated significant differences for the number of video 
correct answers between the two conditions, giving us confidence that the participants were paying more attention to the video under the Video Test Multitasking Condition than under the Video Background Condition. These evidences gave us confidence that our Video Background and Video Test multitasking manipulation was also successful.
In addition, because eight existing classes were used in the study, it was necessary to address the concern whether or not the participants in one condition performed significantly better or worse because of their paired condition. This concern was addressed through a series of $\mathrm{t}$-tests on the numbers of correct answers on reading comprehension by the participants. Table 3 displays the results from the t-tests.

Table 3. T-tests on the Number of Correct Answers in Reading Comprehension under Each Multitasking Condition

\begin{tabular}{lll}
\hline Paired Conditions & $\begin{array}{l}\text { Number of Correct } \\
\text { Answers }\end{array}$ & $t$-tests \\
\hline $\begin{array}{l}\text { All Silence and Video Background Conditions (Groups } \\
\text { \#3 + \#4 in Table 1) }\end{array}$ & 13.93 (in Silence) & $\begin{array}{l}d f=63 \\
t=1.288\end{array}$ \\
$\begin{array}{l}\text { All Silence and Video Test Conditions (Groups \#1 } \\
+ \text { \#2 in Table 1) }\end{array}$ & 12.89 (in Silence) & $p=.203$ \\
& & \\
All Video Background and Silence Conditions (Groups & 13.55 (in Video & \\
\#3 \#4 in Table 1) & Background) & $d f=96$ \\
$\begin{array}{l}\text { All Video Background and Video Test Conditions } \\
\text { (Groups \#5 + \#6 + \#7 + \#8 in Table 1) }\end{array}$ & $\begin{array}{l}13.30 \text { (in Video } \\
\text { Background) }\end{array}$ & $p=.948$ \\
$\begin{array}{l}\text { All Video Test and Silence Conditions (Groups \#1 + \#2 } \\
\text { in Table 1) }\end{array}$ & 12.48 (in Video & \\
$\begin{array}{l}\text { All Video Test and Video Background Conditions } \\
\text { (Groups \#5 + \#6 + \#7 + \#8 in Table 1) }\end{array}$ & 11.97 (in Video & $d f=98$ \\
\end{tabular}

As shown in Table 3, when the participants did reading comprehension in the Silence and the Video Background conditions, they received an average of 13.93 correct answers in reading comprehension in the Silence condition. In comparison, when the participants did reading comprehension in the Silence and Video Test conditions, they received an average of 12.89 correct answers in reading comprehension in the Silence condition. An independent-samples t-test indicates the participants' scores were not significantly different in the Silence condition in the two paired conditions; $d f=63, t=1.288$, $p=.203$. When the participants did reading comprehension in the Video Background and Silence conditions, they received an average of 13.55 correct answers in reading comprehension in the Video Background condition. In comparison, when the participants did reading comprehension in the Video Background and Video Test conditions, they received an average of 13.30 correct answers in reading comprehension in the 
Video Background condition. An independentsamples t-test indicates the participants' scores were not significantly different in the Video Background condition in the two paired conditions; $d f=96, t=.065, p=.948$. Finally, when the participants did reading comprehension in the Video Test and Silence conditions, they received an average of 12.48 correct answers in reading comprehension in the Video Test condition. In comparison, when the participants did reading comprehension in the Video Test and Video Background conditions, they received an average of 11.97 correct answers in reading comprehension in the Video Test condition. An independentsamples t-test indicates the participants' scores were not significantly different in the Video Test condition in the two paired conditions; $d f=98, t=.731, p=.467$. Therefore, it was concluded that the participants were not significantly affected by the multitasking condition pairing to which they were assigned.

\section{Results}

The results (shown in Table 4) indicated that overall the participants scored higher in their reading comprehension under the video background condition (average $75.4 \%$ ) than under the silence (average $74.3 \%$ ) or the video test condition (average $68.3 \%$ ) conditions. Logistic regression $(p<.01)$ and Chi-square analysis $(p<.01)$ indicate that the difference in the number of correct answers between the background (average 75.4\%) and test (average $68.3 \%$ ) conditions was statistically significant.

Table 4. Reading Comprehension Performances: Percent Average of Correct, Wrong, and Blank Answers by Multitasking Conditions and Outcome Intentions

\begin{tabular}{|c|c|c|c|c|c|c|c|c|c|c|c|c|}
\hline \multirow{4}{*}{$\begin{array}{l}\text { Outcome } \\
\text { intentions }\end{array}$} & \multicolumn{12}{|c|}{ Multitasking Conditions } \\
\hline & \multicolumn{3}{|c|}{ Silence condition } & \multicolumn{3}{|c|}{$\begin{array}{l}\text { Video background } \\
\text { condition }\end{array}$} & \multicolumn{3}{|c|}{$\begin{array}{l}\text { Video test } \\
\text { condition }\end{array}$} & \multicolumn{3}{|c|}{$\begin{array}{c}\text { All } \\
\text { conditions }\end{array}$} \\
\hline & $\%$ & $\%$ & $\%$ & $\%$ & $\%$ & $\%$ & $\%$ & $\%$ & $\%$ & $\%$ & $\%$ & $\%$ \\
\hline & Correct & Wrong & Blank & Correct & Wrong & Blank & Correct & Wrong & Blank & Correct & t Wrong & Blank \\
\hline Accuracy & 67.3 & 9.6 & 23.1 & 70.0 & 13.2 & 16.8 & 65.0 & 13.2 & 21.8 & 67.4 & 12.3 & 20.3 \\
\hline $\begin{array}{l}\text { Complet- } \\
\text { ion }\end{array}$ & 81.4 & 17.9 & 0.7 & 80.8 & 18.0 & 1.2 & 71.6 & 26.8 & 1.6 & 77.4 & 21.4 & 1.2 \\
\hline $\begin{array}{c}\text { All } \\
\text { Intentions }\end{array}$ & 74.3 & 13.6 & 12.1 & 75.4 & 15.5 & 9.1 & 68.3 & 20.1 & 11.6 & 72.4 & 16.8 & 10.8 \\
\hline
\end{tabular}

The pattern that the participants' reading comprehension scored better in video background condition than in silence and video test conditions stood out prominently with the Intention for Accuracy, with $70 \%$ average correct answers in background as compared to $67.3 \%$ and $65 \%$ of average correct answers respectively. With the Intention for Completion however, the participants did almost equally well under the silence (average of $81.4 \%$ ) and video background $(80.8 \%)$ conditions. The participants had higher reading comprehension scores with the Intention for Completion (average 77.4\%) 
than with the Intention for Accuracy (average $67.4 \%$ ), although there is an initial possible explanation. Because the instructions for participants under the Intention for Completion was to guess if necessary, it stands to reason that approximately $25 \%$ of their guessedat answers would result in a correct answer due to random chance (each test question had four possible answers). Therefore, the participants' scores were adjusted and they were given credit for $25 \%$ of the questions they simply did not answer when they worked with the Intention for Accuracy. This would reflect what they would have received by just guessing the answers. However, the results indicated that the participants still had a higher percentage of correct answers with the Intention for Completion (77.4\%) than their adjusted scores with the Intention for Accuracy with the additional bonus credits $(72.2 \%)$. Further, while both groups showed their lowest reading comprehension scores under the video test condition, those trying to be complete (average 71.6\%) had much better scores than those trying to be accurate (average $65.0 \%$, difference of $6.6 \%, p<.01$ ). In addition, the participants' reading comprehension score gap between the Intention for Completion and Intention for Accuracy was smaller under the video test condition than under the silence or video background condition. The differences in the latter two conditions between the two Outcome Intentions continued to be significant even when the participants' scores were adjusted with $25 \%$ credit for blank answers (see Figure 1 below).

\section{Reading Comprehension: Examine Percent of Correct Answers through the Lens of Outcome Intentions}

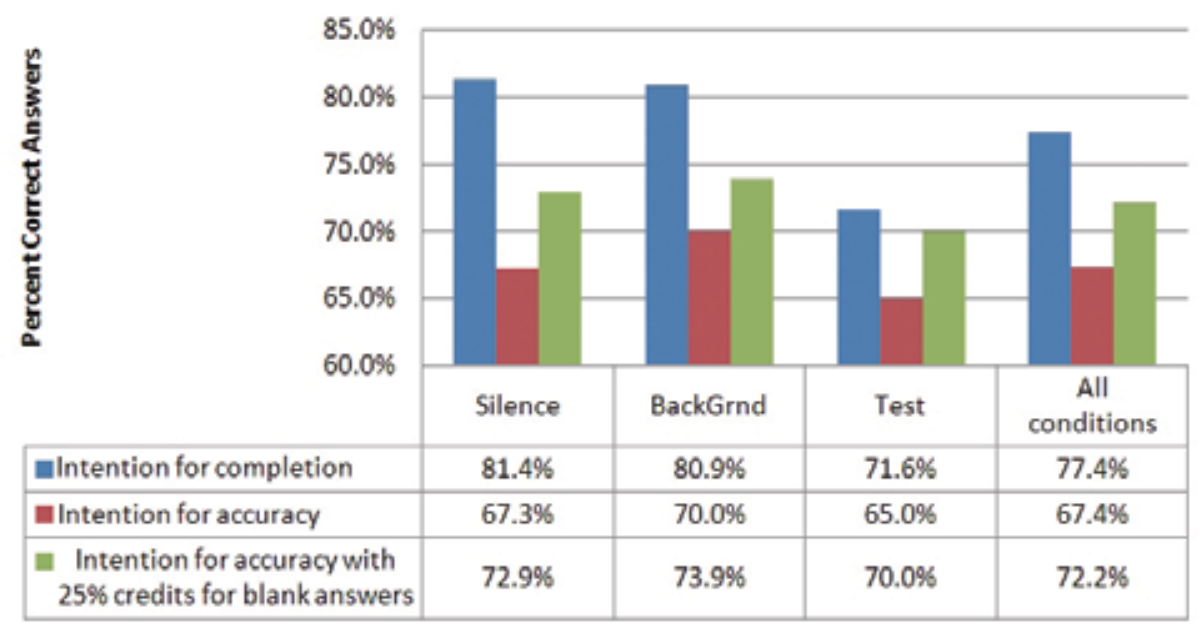

Figure 1. Comparisons of percent correct answers in reading comprehension between the Intention for Completion, Intention for Accuracy, and the Intention for Accuracy with the adjusted credit points given to $25 \%$ of blank answers 
Table 5 shows the percentage of correct answers on the reading tests under silence and background conditions, between Intentions for Completion and Accuracy, and their differences. It also shows the result of a paired- samples student's t-test, a logistic or linear regression test, and a Mann-Whitney's U ranking procedure as indicators for the strength of these differences.

Table 5. Percent Average of Correct Answers in Reading Comprehension by Outcome Intentions: Actual and Adjusted Results under the Silence and Video Background Conditions

\begin{tabular}{lcccccc}
\hline \multirow{2}{*}{$\begin{array}{l}\text { Outcome } \\
\text { Intentions }\end{array}$} & \multicolumn{3}{c}{ Actual Results } & \multicolumn{3}{c}{ Adjusted Results } \\
\cline { 2 - 6 } Accuracy & 67.3 & 70.0 & -2.7 (ns) & 72.9 & 73.9 & $-1.0(\mathrm{~ns})$ \\
Silence & $\begin{array}{c}\text { Video } \\
\text { background }\end{array}$ & Difference & Silence & $\begin{array}{c}\text { Video } \\
\text { background }\end{array}$ & Difference \\
Completion & 81.4 & 80.9 & .5 (ns) & 81.6 & 81.1 & $.5(\mathrm{~ns})$ \\
Difference & -14.1 & -10.9 & & -8.7 & -7.2 & \\
Student's T & $p<.01$ & $p<.01$ & & $p<.01$ & $p<.01$ & \\
Regression & $p<.01$ & $p<.01$ & & $p<.01$ & $p<.01$ & \\
Mann- & & & & & & \\
Whitney's U & $p<.01$ & $p<.01$ & & $p<.01$ & $p<.01$ & \\
\hline
\end{tabular}

As shown in Table 5, participants striving for completion ended with approximately the same score whether they operated in silence (average $81.4 \%$ ) or with a video playing in the background $(80.9 \%$, a drop of just $.5 \%$, $p=\mathrm{ns}$ ), but while striving for accuracy, the participants scored higher while a video played in the background (silence average $67.3 \%$, background average $70.0 \%$, an increase of $2.7 \%, p=\mathrm{ns})$.

Under the Intention for Accuracy, the participants reported nearly identical attention allocations on the video when they strived for
Accuracy as compared to when they strived for Completion. Under the Intention for Completion, the percentage of wrong answers between the silence and video background conditions were nearly identical, but rose dramatically under the test condition. It seemed that the participants with the Intention for Completion were fairly unaffected by the difference between silence and background, but they appeared bothered by the video test condition in that they made more mistakes. Figure 2 below provides the comparison of the reading scores. 


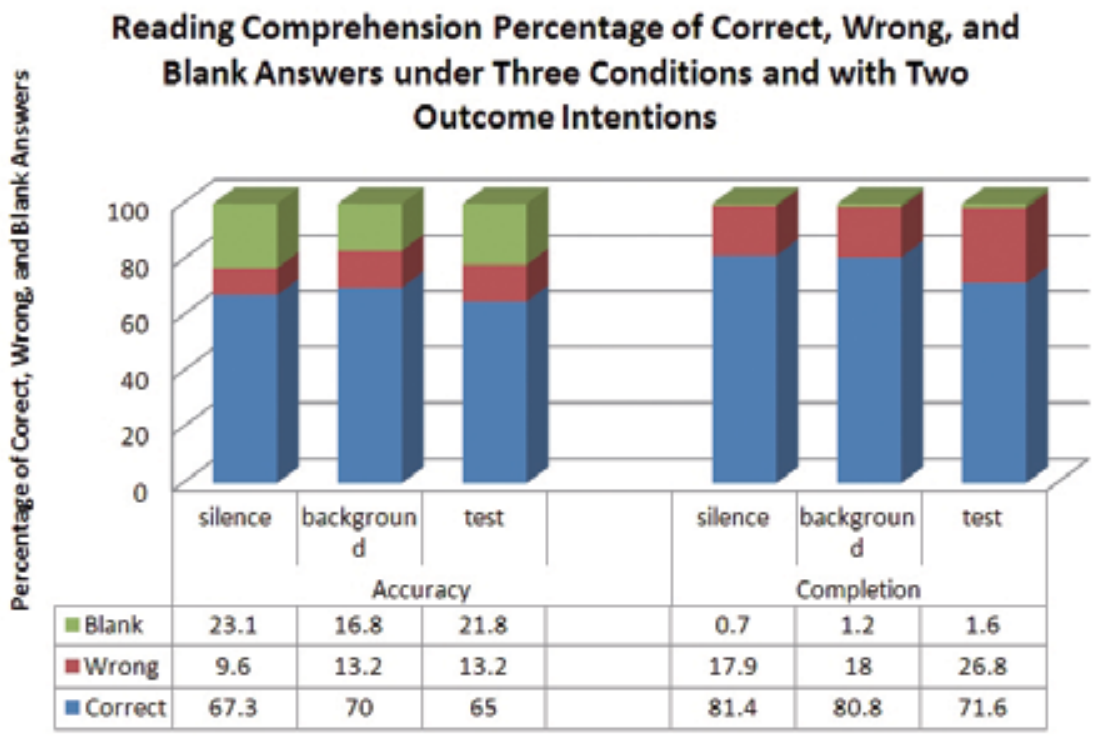

Figure 2. The participants' reading comprehension scores (the percentage of correct, wrong, and blank answers) under three Multitasking Conditions and two Outcome Intentions

\section{Discussion and Implication}

One of the benefits of MUVEs is the richness and complexity of the information they can display, creating something closer to a real-world environment (Dede, 2003; Dede, Ketelhut, \& Reuss, 2003; Nelson, Ketelhut, Clarke, Bowman, \& Dede, 2005), utilizing ill-defined learning outcomes and processes (Barab, Thomas, Dodge, Carteaux, \& Tuzan, 2005; Jonassen, 1999), and requiring a complex set of interactions (Bruckman, 2000) to increase participant engagement and cognitive processing. Similarly, computerbased learning environments incorporate text, video, and pictures to load the learner' $\mathrm{s}$ input channels in a complementary manner and enrich the learner's experiences (Clark \& Mayer, 2003). One of the concerns educators have about these systems is the possibility that multimedia streams, not directly supporting the material, could have a distracting effect on the learner and actually impede the intended learning from the materials (Nelson \& Erlandson, 2008). In a more traditional scenario, educators are concerned that the students, while studying, may be distracted by the background television or the conversations with friends they constantly switch to through text messaging or chat programs (Jackson, 2008). This concern is extended to the increasing acceptance of laptop computers in the classrooms (Fried, 2008). This study targets these concerns in an experiment designed to look at the effects of various levels of video interference on a reading-tolearn situation and how these effects may interact with two different outcome intentions educators could be expecting from their students. Reading comprehension was used to fill the participants' verbal channel and the video to fill the participants' non-verbal or imagery channel. Such a setting allowed mimic of the actual cases to be replicated; namely, watching television while doing homework, communicating with friends while 
studying, or using written materials along with video materials in a multimedia learning presentation (Bruckman, 2000; Dede, 2003; Foehr, 2006).

Findings indicated that students were, indeed, diverting attention away from their reading materials when they were required to pay attention to a video at the same time (the video test condition). This result not only is in line with evidences that have been shown in various dual-task or tasking-switching studies, but also supports the Cognitive Load Theory in that the tested video increased cognitive load, and as a result, negatively affected the learners' ability to process the information. What is of note however, is the difference between the reading performances when the learner strived for accuracy as compared to completion, and when there was a penalty compared to no penalty for wrong answers. When the students were encouraged to complete as many questions as they could and were given the freedom to make mistakes without penalty, they did better. When required to answer each question accurately, such that a penalty would be applied for wrong answers, the participants' scores fell. This difference persisted even when the participants were given a $25 \%$ credit on the blank answers in the Intention for Accuracy.

In this preliminary study, every participant was asked to engage in both Outcome Intentions for Completion and Accuracy, with two sets of reading materials of equivalent difficulty, length, and format. Assuming that the participants' intrinsic cognitive loads were equivalent between the tasks, more stringent the outcome intention appeared to be increased extraneous cognitive load and decreased the resources available for completing a readingto-learn task over a set period of time. In many ways this result is intuitive: if fear of failure alone builds a greater resistance to learning, then the outcomes will likely be more disappointing (Hackman, 1992). The message for designers of multimedia systems is that multitasking may be more suitable when aiming for an overview of the information to be presented than when an exacting knowledge of the information is required. The participants operating under the Intention for Completion generated almost identical results when under the silence and video background conditions. It appears they were neither harmed nor helped by the addition of a background video. This should give some comfort to those who are concerned about students studying at home with the television on or with the unrelated music playing while doing homework. As long as the learner is seeking a general knowledge of the subject and the distraction can be ignored as needed, the learner seems to be able to allocate attentive resources. The learner can switch attention to the main task when required for something more intense or difficult, but apply his or her attentive resources elsewhere when less attention is required on the main task.

In addition, it appears that when the participants worked on their reading task in silence with the Intention for Accuracy, some of their attention simply drifted away to something else. They needed to think of something else and needed a "Daydreaming Attention Manager" of some kind to find something else to think about; all these took away their attentive resources. However, the "Daydreaming Attention Manager" was not needed while the video was played in the background. The participants were already given the "something else" for their daydreaming or wayward attention. Therefore, the attention resources that would have been spent by the Manager were available for their reading task. An analogy to this can be seen in people who prefer to study in a noisy café rather than in a quiet library. The background video may have helped the participants to use 
more resources on the primary task because the secondary task was a given and did not have to be found. In fact, a recent study by Andrade (2010) showed a similar result of the beneficial effect of a secondary task (doodling) on a primary task in that doodling as the secondary task facilitated the primary task by reducing daydreaming. The background video was suspected to have also served as something to prevent participants from daydreaming when they were completing their reading tasks.

In summary, three issues deserve further attention and discussion. The first is the need for multimedia system designers to consider the level of the information presented (detailed versus general) when loading both of the learner's input channels (verbal and nonverbal)with essential information, the second type of cognitive overload scenario presented by Mayer and Moreno (2003). Multitasking may be more suitable when a general than a detailed level of information is to be assimilated. The second implication is the use of a secondary non-essential task as a means to focus more of the learner's resources on the primary task. According to Mayer and Moreno (2003), learners experience the third type of cognitive overload when a mix of essential and incidental information is presented during a learning process. Our study indicates that the issue may be more complex. Although it is too soon to jump to the conclusion, the result of the study suggested that the incidental information might sometimes help the acquisition of the essential information when the information was channeled through different senses. That is, it may happen that our students study better when the television is playing in the background. This may be because the incidental information and the stimulation of different senses allowed the part of attention that would daydream to find a place to operate without attentive resources having to be spent finding such a place. Or this may be because the additional stimulation forced the students to try harder to focus and get better results on their primary task when distractions are competing for their attentive resources. Obviously, more research is necessary to examine the real cause of the issue. The third implication is related to the consideration test-designers need to give to the output intention projected within a timelimited test. The deteriorating effect of the Intention for Accuracy appears to operate regardless of multitasking conditions, and assessment results should be interpreted in light of the outcome intention thrust upon the test-takers.

\section{Conclusion}

Multitasking is an increasingly popular activity in the way we live our lives, so it would benefit us to understand how multitasking works, its outcomes, and moderators of its effectiveness. There are many powerful outcomes at stake: the car that loses its guidance on the highway, the student who does not learn what he or she must know for the next major challenge, or the learning system that was a great idea, but just did not work. This study extended our understanding of the impact of outcome intentions on students' reading comprehension and multitasking abilities. Our data indicate that students performed better with the Intention for Completion than with the Intention for Accuracy, and that the unobtrusive background video likely reduced daydreaming and helped students focus better in processing their primary reading tasks. These findings will hopefully help inform the researchers, designers, and educational practitioners to conceptualize, design, and construct multimedia learning environments that will help improve students' ability to focus, read, understand, and learn. 


\section{References}

Andrade, J. (2010). What does doodling do? Applied Cognitive Psychology, 24, 100-106.

Baddeley, A., Chincotta, D., \& Adlam, A. (2001). Working memory and the control of action: evidence from task switching. Journal of Experimental Psychology: General, 130(4), 641-657.

Barab, S. A., Thomas, M., Dodge, T., Carteaux, R., \& Tuzan, H. (2005). Making learning fun: Quest Atlantis, a game without guns. Educational Technology, Research, and Development, 53(1), 86-108.

Bruckman, A. (2000). Uneven achievement in a constructivist learning environment. Paper presented at the International Conference on Learning Sciences, Ann Arbor, MI.

Burgess, P. W., Veitch, E., de Lacy Costello, A., \& Shallice, T. (2000). The cognitive and neuro-anatomical correlates of multitasking. Neuropsychologia, 38(6), 848-863.

Carr, N. (2010). The Shallows: What the Internet Is Doing to Our Brains. NYC: W.W. Norton \& Company.

Clark, R. C. \& Mayer, R. E. (2003). E-learning and the science of instruction: Proven guidelines for consumers and designers of multimedia learning. San Francisco: Pfeiffer.

Dede, C. (2003). Multi-user virtual environments. Educause Review, 38(3), 60-61.

Dede, C., Ketelhut, D. J., \& Reuss, K. (2003). Motivation, usability, and learning outcomes in a prototype museum-based multi-user virtual environment. Paper presented at the Fifth International Conference of the Learning Sciences.

Diamond, A. (2002). Normal development of prefrontal cortex from birth to young adulthood: Cognitive functions, anatomy, and biochemistry. In D. T. Stuss \& R. T. Knight (Eds.), Principles of Frontal Lobe Function. Oxford, England: Oxford University Press.

Foehr, U. G. (2006). Media multitasking among American youth: Prevalence, predictors, and pairings. Menlo Park, CA: Kaiser Family Foundation.

Fried, C. B. (2008). In-class laptop use and its effects on student learning. Computers \& Education, 50, 906-914.

Gee, J. P. (2003). What video games have to teach us about learning and literacy. New York: Palgrave Macmillan.

Hackman, J. R. (1992). Group influences on individuals in organizations. In M. D. Dunnette \& L. M. Hough (Eds.), Handbook of Industrial and Organizational Psychology (Vol. 3) (pp. 199-268). Palo Alto: Consulting Psychologists Press, Inc.

Jackson, M. (2008). Distracted: The Erosion of Attention and the Coming Dark Age. New York: Prometheus Books.

Jaeggi, S. M., Buschkuehl, M., Jonides, J., \& Perrig, W. J. (2008). Improving fluid intelligence with training on working memory. Proceedings of the National Academy of Sciences, USA. 105(19), 6829-33.

Johnson, S. B. (2005). Everything bad is good for you: How today's popular culture is actually making us smarter. New York: The Penguin Group.

Jonassen, D. H. (1999). Designing constructivist learning environments. In Reigelugh (Ed.), Instructional design theories and models: A new paradigm of instructional theory (Vol. 2) (pp. 217-239). Mahwah: Lawrence Erlbaum Associates, Inc.

Just, M. A., Keller, T. A., \& Cynkar, J. A. (2008). A decrease in brain activation associated with driving when listening to 
someone speak. Brain Research, 1205, 70-80.

Kalyuga, S., Chandler, P., Sweller, J. (2000). Incorporating learner experience into the design of multimedia instruction. Journal of Educational Psychology, 92(1), 126-136.

Kincaid, J. P., Fishburne, R. P., Rogers, R. L., \& Chissom, B. S. (1975). Derivation of new readability formulas (Automated Readability Index, Fog Count and Flesch Reading Ease Formula) for Navy enlisted personnel). Research Branch Report 8-75, Millington, TN: Naval Technical Training, U. S. Naval Air Station, Memphis, TN.

Kirschner, P. A. (2002). Cognitive load theory: Implications of cognitive load theory on the design of learning. Learning \& Instruction, 12(1), 1-10.

Lang, A. (2001). The limited capacity model of mediated message processing. Journal of Communication, 46-70.

Mayer, R. (2001). Multimedia Learning. Cambridge University Press.

Mayer, R. E., \& Clark, R. C. (2007). Using rich media wisely. In R.A. Reiser \& J.V.

Dempsey (Eds.) Trends and issues in instructional design and technology (pp. 311-322). New Jersey: Pearson Education, Inc.

Mayer, R. E., \& Moreno, R. (2003). Nine ways to reduce cognitive load in multimedia learning. Educational Psychologist, 38(1), 43-52.

Meyer, D. E., \& Kieras, D. E. (1997). A Computational Theory of Executive Cognitive Processes and Multiple-task Performance: Part 1. Basic Mechanisms. Psychological Review, 104, 229-233.

Miller, G. A. (1956). The magical number seven, plus or minus two: Some limits on our capacity for processing information. Psychological Review, 63, 81-97.

Monsell, S., \& Driver, J. (2000). Control of cognitive processes: attention and performance XVIII. Cambridge, Mass:
MIT Press.

Nelson, B., \& Erlandson, B. E. (2008). Managing cognitive load in educational multi-user virtual environments: reflection on design practice. Educational Technology, Research, and Development, 56, 619-641.

Nelson, B., Ketelhut, D., Clarke, J., Bowman, C., \& Dede, C. (2005). Design-based research strategies for developing a scientific inquiry curriculum in a multiuser virtual environment. Educational Technology, 45(1), 21-27.

Paas, F. G., Tuovinen, J. E., Tabbers, H., \& van Gerven, P. W. M. (2003). Cognitive load measurement as a means to advance cognitive load theory. Educational Psychologist, 38(1), 63-71.

Paivio, A. (1986). Mental representations. New York: Oxford University Press.

Poldrack, R. A., \& Foerde, K. (2007). Category learning and the memory systems debate. Neuroscience and Biobehavioral Reviews, 32, 197-205.

Prensky, M. (2001). Digital game-based learning. Columbus, $\mathrm{OH}$ : McGraw-Hill.

Rushton, A., Oxley, J., \& Croucher, P. (2000). The handbook of logistics and distribution management (2nd ed.). London: Kogan Page.

Ruthruff, E., Van, S. M., Johnston, J. C., \& Remington, R. (2006) How does practice reduce dual-task interference: Integration, automatization, or just stage-shortening? Psychological Research, 70, 125-142.

Schweickert, R., \& Boggs, G. J. (1984). Models of central capacity and concurrency. Journal of Mathematical Psychology, 28, 223--281.

Small, G., \& Vorgan, G. (2009). iBrain: Surviving the Technological Alteration of the Modern Mind. New York: HarperCollins Publisher.

Sweller, J. (1988). Cognitive load during problem solving: Effects on learning. Cognitive Science, 12(2), 257-285. 
Tuovinen, J., \& Pass, F. G. W. C. (2004. Exploring multidimensional approaches to the efficiency of instructional conditions. Instructional Science, 32, 133-152.

Wilson, R. (1972). Social choice theory without the Pareto Principle. Journal of Economic Theory, 5(3), 478-486.

\section{Contact the Authors}

\section{Lin Lin}

University of North Texas

Email: Lin.Lin@unt.edu

Adrian Robertson

Montana State University Billings1

Email: tip.robertson@msubillings.edu

Jennifer Lee

University of North Texas

Email: Jennifer.Lee@unt.edu 